\title{
Reflections on the challenges and opportunities for palliative care in Nepal
}

\author{
Daniel Munday ${ }^{a}$, Ruth Powys ${ }^{b}$ \\ ${ }^{a}$ PhD FRCP MRCGP FFARCSI DipPallMed PGCertMedEd DRCOG MBBS, Consultant Advisor in Palliative Care \\ and Health Services Research, International Nepal Fellowship, Nepal \\ ${ }^{\mathrm{b}}$ MBBS MPC FAChPM, Consultant Advisor in Palliative Care, International Nepal Fellowship, Nepal
}

\begin{abstract}
Palliative care in Nepal has been developing over the last 20 years, led by pioneering doctors and nurses who have gained experience in the specialty, often while working overseas, or who have had the opportunity to do clinical attachments abroad. Recently, in collaboration with international palliative care specialists, a national strategy has been developed and adopted to guide future development so that palliative care for all who need it can be provided. This article explores the faith-based context for palliative care and describes the particular issues Nepal faces, the work of Christian mission organizations in supporting palliative care development, and the need for religious and cultural sensitivity.
\end{abstract}

\section{Faith and the Development of Hospice and Palliative Care}

Care of the dying is a recognized part of nearly all ancient religious philosophies and ways of life. Nepal is a majority Hindu country with a sizeable Buddhist population, each with its own beliefs and practices around the end of life and after death.

In Hindu philosophy, death is not seen as being the opposite of life, but the opposite of birth. ${ }^{1}$ Death is a process whereby the soul migrates to the next life or to heaven. The soul is enabled to transmigrate by various rituals being observed, such as cremation taking place in sacred places near to water. The famous Pashupathinath Aryan Ghat on the banks of the Bagmati River, a tributary of the sacred Ganges, is traditionally where cremations take place in Kathmandu. Faithful Hindus may prepare for death by travelling there, as some Indians travel to the holy city of Banares in preparation for death. ${ }^{2}$ An ashram has been provided on the Pashupatinath site, where the old, infirm, and those who are dying are often brought and cared for. In recent years, this service has incorporated some of the practices and principles of modern palliative care. ${ }^{3}$ (see figure 1).

Nov 2017. Christian Journal for Global Health 4(3):12-20 
Figure 1 - The 'Hospice' Ashram at Pashupatinath Temple (note the body prepared for cremation in the foreground).

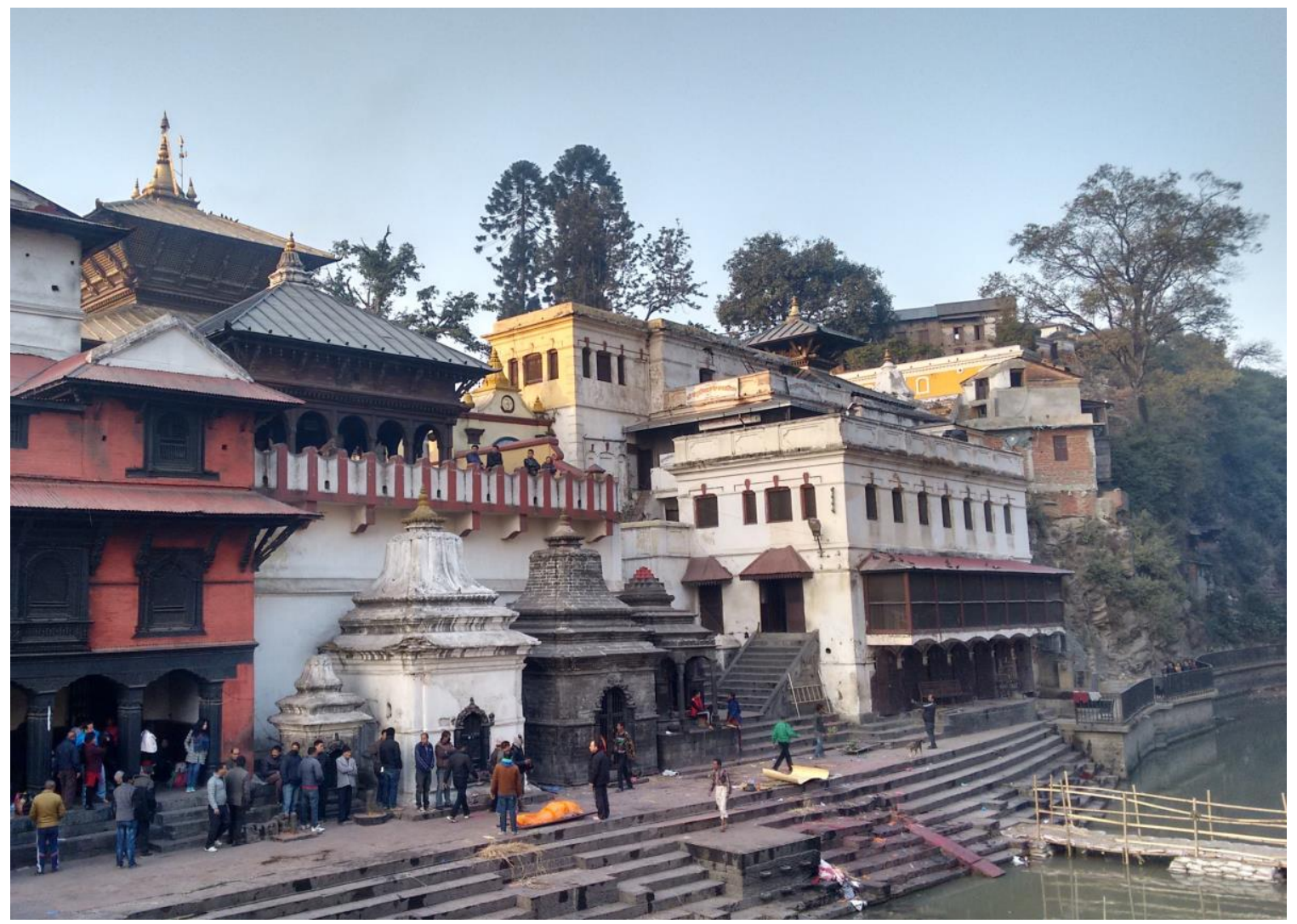

While Buddhists also believe in the transmigration of the soul, pre-death rituals and the site of death are not so important. In Buddhist philosophy, one should always be ready for death and banish all fear of it. ${ }^{4}$ Buddhists prepare for death by caring for the dying person, particularly for their psychological and spiritual state, keeping them calm and focused, enabling them to progress smoothly to the next life. ${ }^{5}$ Caring for those who are dying is an important service to perform and Karuna-Shechen, a Buddhist charity, set up a hospice in 2000 as part of a medical service in the grounds of the Shechen Monastery in Bouddha, an area of Kathmandu with a large Tibetan Buddhist population.

For Christians, palliative care with its holistic, patient-centered approach resonates with the principles Jesus summarizes in the Great Commandments - love God, and love your neighbor as yourself. Ferngren suggests, "It was the Christian belief in personal and corporate philanthropy as an outworking of Christian concepts of agape and the inherent worth of individuals who bore God's image that introduced into the classical world the concept of social responsibility in treating epidemic disease." Christians, caring for people suffering with plague, were potentially a significant contributor to the rapid church growth of the second and third centuries. ${ }^{7}$

Early Christianity adapted Jewish service ideals of generosity and hospitality, linking these to faith and salvation, especially by serving the poor and afflicted. As Christianity spread and developed, institutions to care for the sick and destitute were established frequently linked to places of worship and monasteries. ${ }^{6}$ Hospices, as places to care for the sick and dying traveler, were set up by the 
Knights Hospitaller in the $14^{\text {th }}$ Century during the time of the Crusades. ${ }^{8}$

Increasing formalization of services with development of institutions later led to depersonalization, segregation, and commercialization of health services. ${ }^{8}$ Catholic and Protestant missionary revivals of the $19^{\text {th }}$ Century led to the establishment of hospices to care for the dying such as the Hospice of the Association des Dames de Calvaire in Lyon and that of the Sisters of Charity in Dublin. Towards the turn of the $20^{\text {th }}$ Century in London, amongst other Christian institutions founded to care for the dying, was the Hospital of St John and St Elizabeth and St Lukes' and St Joseph's Hospices, ${ }^{9}$ where Dame Cicely Saunders, founder of the modern hospice movement was later to work. ${ }^{10} \mathrm{Up}$ until the development of the modern hospice movement in the UK, most hospices were Christian charities. ${ }^{7}$

\section{Palliative Care in Low and Middle- income Countries}

Palliative care services are developing in low- and middle-income countries, with Christian organizations often at the forefront. Palliative care embraces a holistic approach with patient-centered care spanning physical, psychological, social, and spiritual domains. However, for care to be effective, models, in addition, need to be socially, economically, and culturally appropriate. With reduced health resources and individual poverty, normally treatable conditions may well be palliative at an earlier stage in low-income settings. This can include acute surgical conditions such as major burns or acute abdomens occurring in remote or inaccessible areas that lack services and clinicians able to provide necessary curative care, medical conditions requiring intensive care, or where resistance to treatment has emerged (e.g., HIV/AIDS or multidrug-resistant TB). ${ }^{11}$
As hospice and palliative care services developed in industrialized settings, their main focus was on advanced cancer. ${ }^{12}$ In Africa, particularly, palliative care developed to care for huge numbers suffering from HIV/AIDS. ${ }^{13}$

Palliative care has also responded to local and more esoteric needs, for instance, with an innovative approach to end-of-life care for patients suffering from rabies in an infectious diseases hospital in Manilla and a service focusing on the palliative needs of the transgender population in Delhi. ${ }^{14,15}$

Currently, the demographics of nearly every country is changing with ageing population trends, but in low- and middleincome countries, this demographic change is particularly significant with a rapid increase in Non-Communicable Disease (NCD) in areas where death was previously commonly due to infections and maternal and child health conditions. ${ }^{16}$ Nepal, compared to other lowincome countries, is ahead of the curve, with already $60 \%$ of deaths occurring from NCDs according to WHO modelling. ${ }^{17}$

\section{Palliative Care Development in}

\section{Nepal}

Nepal is a low-income country reported as being 145 out of 187 countries globally in terms of its UN Human Development Index. ${ }^{18}$ The geography of Nepal is hugely varied and challenging, with the high Himalayan range in the North, hills in the Central Zone, and plains (Terai) on the southern border with India. In Nepal, eighty-three per cent of the population lives in rural areas that can be very remote. It can take up to 4 days to reach the nearest district level health facilities. ${ }^{19}$ Nepal's health care system is based on local health posts, referring up to district, zonal, regional, and tertiary hospitals. Health, in general, in Nepal has improved with life expectancy, increasing from 45 to 69 years between the mid 1980s and

Nov 2017. Christian Journal for Global Health 4(3):12-20 
today; ${ }^{20}$ however, much of the focus of healthcare provision has until recently concentrated on achieving the Millennium Development Goals. This has led to some marked successes; for instance, maternal mortality rates have reduced from 870 per 100,000 live births in 1990 to 380 per 100,000 by $2008 .^{21}$ Despite these achievements, universal health coverage remains a somewhat distant aspiration.

Palliative care in Nepal started to emerge in the late 1990s with cancer specialist doctors, nurses, and others becoming aware of the specialty through working in other countries or having had the opportunity to study abroad. The first modern hospice was established in 2000 in the capital, Kathmandu, followed by others, either stand alone hospices or palliative care units, part of cancer hospitals mostly in Kathmandu or other major cities. ${ }^{22}$ Also, there has been interest and support from abroad, particularly through the International Network for Cancer Treatment and Research (INCTR). ${ }^{22}$ The Nepalese Association of Palliative Care (NAPCare) was established in 2009, bringing together those interested in palliative care and providing a vehicle for training and advocacy. In 2013, the Ministry of Health established a two-week introductory course, facilitated by NAPCare. Through the efforts of the NAPCare community, supported by the Pain and Palliative Care Policy Unit in Wisconsin, morphine has been made available in palliative care formulations manufactured in Nepal by a Nepalese pharmaceutical company. ${ }^{23}$

Palliative care is still a relatively new specialty for Nepal, and there is only one Nepali trained medical palliative care specialist, a limited number of experienced Nepali palliative care nurses, and almost no trained palliative care allied health professionals. Early palliative care in Nepal was mainly cancerfocused. Cancer is a significant palliative care issue since although only around $8 \%$ of deaths are due to cancer, up to $75 \%$ of people are in an advanced stage at the time of diagnosis. ${ }^{24}$ HIV/AIDs is an issue mainly within specific subgroups of migrants and sex workers across the open border with India, but the epidemic remains numerically small overall. ${ }^{25}$ Our own survey of an inpatient unit in a mission hospital in Western Nepal revealed that chronic respiratory illness was by far the most common illness requiring palliative care. $^{26} \mathrm{~A}$ recent survey in one rural area has indicated that chronic disease management (CDM) is a significant challenge, and most people with a chronic illness do not receive any effective management (paper in preparation), so any palliative care intervention in rural areas will need to be embedded within the context of the spectrum of CDM.

In Nepal, like other low- and middleincome countries with little subsidized health care or health insurance, catastrophic household debt can easily be precipitated by health expenditure, particularly from accessing the private sector. ${ }^{27}$ This health expenditure can often be futile in people with advanced noncurable illnesses. Palliative care training can empower health workers in remote, rural areas to care for people with good symptom management, rather than sending patients \& families away for clearly inappropriate and expensive treatment. So palliative care can have a significant role in the reduction of poverty for surviving family members. ${ }^{28}$

\section{Challenges for Nepal}

The number of frail elderly is increasing in Nepal, as people live longer, with a 2011 survey reporting that over $65 \mathrm{~s}$ made up $6 \%$ of the population, increasing from $4 \%$ over seven years. ${ }^{29}$ As a result, there is a rapidly increasing incidence of multi-morbidity and complex medical issues associated with increasing NCDs in an aging population. ${ }^{30}$ In industrialized 
countries, geriatrics and palliative care have developed as separate specialties. However, for low- and middle-income countries, this may not be a replicable model due to limitations in health resources. New ways of developing care of the elderly including palliative care need to be explored. ${ }^{31}$

Nepal is experiencing another significant demographic shift as many of the younger generation move from their rural homes to other parts of Nepal for work, or, increasingly, leaving Nepal as migrant workers or for opportunities to study abroad. The Nepal Household Survey 2012 revealed 27\% households have at least one family member working overseas and $28 \%$ of households have female heads. ${ }^{29}$ In addition, many mothers with school age children will migrate from rural areas to the city for education. This means that the traditional extended family structure that has supported the elderly and infirm is now breaking down, and an increasing number of older people are living alone. ${ }^{32}$

Palliative care development in Nepal needs to be considered in its particular geographical, demographic, and economic context. Its low-income status is reflected in its rudimentary healthcare provision, particularly in rural areas. However, with its burgeoning incidence of NCDs, palliative care is an important facet of universal health coverage if the people are to have access to the type of healthcare they need. Over the last two years, NAPCare along with partners from the Government of Nepal, WHO, and some international partners has been involved in developing a national strategy. This takes a public health approach $^{33}$ with the aim of integrating palliative care into the health system of Nepal so it is available to all who need it. The Ministry of Health in Nepal has now adopted the strategy as government policy. ${ }^{34}$

\section{Serving the Poor and Marginalized}

In Nepal, two Christian INGOs, United Mission to Nepal (UMN), and International Nepal Fellowship (INF) have been seeking to serve the poor and marginalized for over 6 decades. ${ }^{35}$ This has been done through health and community development, education, and various innovative models of economic and industrial development. UMN and INF have both established mission hospitals that seek to model holistic care. ${ }^{35} 36$ Under INF's umbrella, this concern for the poor and marginalized has led to health work with people affected by leprosy, TB, spinal cord injuries, and those needing rehabilitation. Over the past 4 years, this has expanded to the inclusion of palliative care development at both the local hospital level and in partnership with NAPCare on a national level. Through supporting Nepali colleagues, the INF program has included needs assessment research (funded by the health development charity EMMS International), education, and advising on the development of the national strategy.

The church in Nepal has been in existence for 60 years and now has a greater vision for social outreach to care for the vulnerable in surrounding communities. ${ }^{35}$ Following the 2015 earthquake, churches and Christian organizations, along with many others, reached out to those in need. Churches are recognizing the increasing numbers of frail aged members and others in their communities who have significant care needs. Up to the present, there have been almost no old-age homes in Nepal, but there is a need emerging as the extended family support system is breaking down. A few churches are already responding to this need in appropriate ways. Churches are also requesting and receiving training for volunteer members to learn about caring for the frail elderly and those with palliative care needs. ${ }^{37}$ There is great potential to expand this type of community 
training with community groups including churches and others, although whether community palliative care services similar to those in Kerala $^{38}$ can be established remains to be seen.

\section{Cultural and Religious}

\section{Considerations}

In Nepal, as in India, most people believe in God and are religious. ${ }^{39}$ Religious practices are very evident and commonly observed in temples, roadside shrines, and around peoples' shops and houses as an aspect of everyday life. On the day of writing, people in Nepal are honoring the "eternal spirit" in dogs, placing garlands around their necks and tikkas on their foreheads. For those from other cultures, some practices can seem strange. One of the authors was struck whilst visiting the ashram at Pashupatinath (see figure 1) by the thick smoke from a funeral pyre seeping into the room where a person was dying. When he inquired how dying people reacted to this, the response was that they found it comforting, as the smoke and aroma reminded them that they were "passing on" in a holy place.

Hospices, even those that are not religious, will often have prominent pictures of Hindu deities that patients frequently find comforting and give them a focus for spiritual care. ${ }^{41}$ Water containing tulsi (holy basil) leaves are given to a dying person to aid passage of their soul to the next life. Hospices (and many houses) have tulsi plants growing in their gardens. Another ritual of enabling the dying person to hold onto the tail of a cow is similarly said to enable the soul's passage, ${ }^{42}$ and we have also observed this practice in a hospice garden. It is important, when working with those from other faiths and cultures, to seek to understand the customs and rituals and so be able to practice in a way that is respectful and enabling to patients and their families.
For the Christian, practicing palliative care is often seen as part of the calling to serve the poor, marginalized, and those who suffer. Unlike Nepal, in India, Christians were at the forefront of palliative care provision in the early days of its development. This was not without some concern that Christians caring for those of other faiths could lead to difficulties, including conflict in families if the dying person wanted to convert. ${ }^{42}$ It is vital that Christians caring for those of other faiths and cultures understand and respect their beliefs and practices, particularly at a time of great vulnerability, such as for the patient receiving palliative care.

In our travelling in India and Nepal, we have also observed that Christian hospitals have often developed a culture of patient centered medicine upon which palliative care services can be built. Of course, such an approach is not exclusive to Christian hospitals, but such patient centered institutions can provide excellent sites for palliative care model development and training, as we are currently piloting in one large mission hospital in West Nepal. So, we believe that Christian health care institutions can play an important role in the development of palliative care in Nepal as they have been doing in India, for instance, in the Emmanuel Hospital Association palliative care programme. $^{43}$

\section{Conclusion}

Palliative care in the majority Hindu country of Nepal has been developing over the last 20 years. Recently, Nepal has established a palliative care strategy to guide development of appropriate palliative care over the next 10 years. This has been led by the NAPCare, supported by expatriate specialist physicians from INF. They have been undertaking needs assessment research to promote an evidencebased approach to palliative care development in Nepal. The next step for the Nepali palliative

Nov 2017. Christian Journal for Global Health 4(3):12-20 
care community and its supporters is working toward implementation of the national strategy.

Palliative care development in Nepal aims to identify and respond to the local needs and contexts in an appropriate way, which is respectful to local customs and religious practices. Appropriate palliative care will necessitate incorporating end-stage care into emerging chronic disease management models, establishing frail elderly care, and defining appropriate models for rural and remote areas. There continues to be a need for overseas trained palliative care clinicians to be involved in supporting palliative care development, particularly, in the coming few years while more national staff can be trained and gain experience. Christian health care workers have an opportunity to be a part of this.

Local churches can take a lead in developing social care in their communities and can respond to the need for elderly and palliative care by setting up volunteer services and collaborating to serve their communities. In this way, they will carry on the Christian tradition of caring for the sick and dying established nearly two millennia ago.

\section{References}

1. Inbadas H. Indian philosophical foundations of spirituality at the end of life. Mortality 2017:114.

https://doi.org/10.1080/13576275.2017.1351936

2. Justice C. Dying the good death: The pilgrimage to die in India's holy city. New York: State University of New York; 1997.

3. Shrestha S. Challenges and solutions for developing palliative care in Nepal [last cited 2015 Dec 19]. Palliative Care in Oncology Symposium 2015 [Internet] 2015 Sept 10. Available from: http://pallonc.org/challenges $\% \mathrm{C} 2 \% \mathrm{AD}$-and$\% \mathrm{C} 2 \%$ ADsolutions- \%C2\%ADdeveloping$\% \mathrm{C} 2 \%$ ADpalliative-\%C2\%ADcare$\% \mathrm{C} 2 \%$ ADnepal
4. Masel EK, Schur S, Watzke HH. Life is uncertain. Death is certain. Buddhism and palliative care. J Pain Symptom Manag. 2012;44(2):307-12. https://doi.org/10.1016/j.jpainsymman.2012.02.0 $\underline{18}$

5. Puchalski CM, O’Donnell E. Religious and spiritual beliefs in end of life care: how major religions view death and dying. Tech Reg Anesth Pain Manag. 2005;9(3):114-21. https://doi.org/10.1053/j.trap.2005.06.003

6. Ferngren GB. Medicine and health care in early Christianity. Baltimore: JHU Press; 2016. 264 p. [p. 117].

7. Stark R. Epidemics, networks, and the rise of Christianity. Semeia.1992;56:159-75.

8. Lutz S. The history of hospice and palliative care. Curr Prob Cancer 2011;35(6):304-9. https://doi.org/10.1016/j.currproblcancer.2011.1 $\underline{0.004}$

9. Lewis MJ. Medicine and care of the dying: a modern history. New York: Oxford University Press; 2007.

10 .Clark D. Originating a movement: Cicely Saunders and the development of St Christopher's Hospice, 1957 - 1967. Mortality. 1998;3:43-63. https://doi.org/10.1080/713685885

11 Munday D, Powys R, BK M, Murray S, Boyd K. Adapting the supportive and palliative care indicator tool (SPICT) for use in rural Nepal. 24th International Congress of the Indian Association of Palliative Care. Coimbatore, Tamil Nadu: Ind J Palliative Care. 2017:121-79.

12. Clark D. From margins to centre: a review of the history of palliative care in cancer. Lancet Oncology. 2007;8(5):430-8. https://doi.org/10.1016/S1470-2045(07)70138-9

13. Harding R, Higginson IJ. Palliative care in SubSaharan Africa. Lancet. 2005;365 (9475):19717. https://doi.org/10.1016/S01406736(05)66666-4

14. Marsden SC, Cabanban CR. Rabies: a significant palliative care issue. Prog Palliative Care. 2006;14(2):62-7. https://doi.org/10.1179/174329113X137898286 $\underline{89145}$

15. Doumai S. Hidden lives, hidden 
patients in transgenders (LGBT): Shalom Delhi caring for transgenders living with HIV. 24th International Congress of the Indian Association of Palliative Care; 2017; Coimbatore, Tamil Nadu: Ind J Palliative Care; 2017. p. 121- 79.

16. WHO. Global action plan for the prevention and control of noncommunicable diseases 20132020. Geneva: World Health Organisation; 2013.

17. WHO. NCD country profiles: Nepal. Secondary NCD country profiles [last accessed 2017 October 19]: Nepal: World Health Organisation; 2014. Available from: http://www.who.int/nmh/countries/npl_en.pdf?u $\underline{\mathrm{a}=1}$

18. Malik K. Human development report 2014: sustaining human progress: reducing vulnerabilities and building resilience. United Nations Development Programme; 2014.

19. Central Bureau of Statistics. National population and housing census 2011. National Report. Kathmandu, Nepal: Nepal; 2012.

20. World Bank. Life expectancy in Nepal [last cited 2017 October 19]. Available from: https://data.worldbank.org/country/Nepal

21. Malla DS, Giri K, Karki C, Chaudhary P. Achieving millennium development goals 4 and 5 in Nepal. BJOG. 2011;118(s2):60-8. https://doi.org/10.1111/j.14710528.2011.03113.x

22. Brown S, Black F, Vaidya P, Shrestha S, Ennals D, LeBaron VT.. Palliative care development: the Nepal model. J Pain Symptom Manag. 2007;33(5):573-7. https://doi.org/10.1016/j.jpainsymman.2007.02.0 09

23. Paudel BD, Ryan KM, Brown MS, Krakauer EL, Rajagopal MR, Maurer MA, et al. Opioid availability and palliative care in Nepal: influence of an international pain policy fellowship. J Pain Symptom Manag. 2015;49(1):110-6.: https://doi.org/10.1016/j.jpainsymman.2014.02.0 $\underline{11}$

24. Piya MK, Acharya SC. Oncology in Nepal. S Asian J Cancer. 2012;1(1):5 https://doi.org/10.4103/2278-330X.96490

25. Nepal B. Population mobility and spread of HIV across the Indo-Nepal border. J Health Popul Nutr. 2007;25(3):267-77.

26. BK M, Munday D, Powys R. Non-communicable diseases and palliative care needs: a survey of a rural hospital in Nepal. 24th International Congress of the Indian Association of Palliative Care; 2017; Coimbatore, Tamil Nadu: Ind J Palliative Care; 2017:121-79.

27. Saito E, Gilmour S, Rahman MM, Gautam GS, Shrestha PK, Shibuya K. Catastrophic household expenditure on health in Nepal: a cross-sectional survey. Bulletin of the World Health Organization. 2014;92:760-67. https://doi.org/10.2471/BLT.13.126615

28. Ratcliff C, Thyle A, Duomai S, Manak M. Poverty reduction in India through palliative care: a pilot project. Ind J Palliative Care. 2017;23(1):41-45. https://doi.org/10.4103/0973$\underline{1075.197943}$

29. Ministry of Health and Population. Nepal demographic and health survey 2011. Kathmandu, Nepal: Nepal; 2012.

30. Mishra SR, Neupane D, Bhandari PM, Khanal V, Kallestrup P. Burgeoning burden of noncommunicable diseases in Nepal: a scoping review. Globalization Health. 2015; 11 (1). https://doi.org/10.1186/s12992-015-0119-7

31. Humphreys G. The health-care challenges posed by population ageing. Bulletin of the World Health Organization. 2012;90:82-3. https://doi.org/10.2471/BLT.12.020212

32. Gartaula HN. International migration and local development in Nepal. Contrib Nepalese Studies. 2009;36(1):37-65.

33. Stjernswärd J, Foley KM, Ferris FD. The public health strategy for palliative care. J Pain Symptom Manag. 2007;33(5):486-93. https://doi.org/10.1016/j.jpainsymman.2007.02.0 16

34. Munday D. National strategy for palliative care handed over to the Government of Nepal [last accessed 2017 Sep 14]. eHospice 2017; 25 April 2017. Available from: http://www.ehospice.com/ArticleView/tabid/106 86/ArticleId/21936/View.aspx

35. Hale T. Light dawns in Nepal: a story about ordinary people used by God to do the impossible: the story of the International Nepal 
Fellowship. Kathmandu: International Nepal Fellowship; 2012.

36. Harper I. Mediating therapeutic uncertainty: a mission hospital in Nepal. In: Harrison M, Jones $\mathrm{M}$, Sweet H, eds. From Western medicine to global medicine: the hospital beyond the West. Delhi: Orient Longman; 2008.

37. Russell R. Mobilising the community for the provision of palliative care in Nepal. eHospice 2016; 17 June 2016. Available from: https://www.ehospice.com/default.aspx?tabid=1 0686\&ArticleId $=19728$

38. Sallnow L, Kumar S, Numpeli M. Home-based palliative care in Kerala, India: the neighbourhood network in palliative care. Progress in Palliative Care. 2010;18(1):14-7. https://doi.org/10.1179/096992610X126242902 $\underline{76142}$

39. Mishra S, Bhatnagar S, Philip FA, et al. Psychosocial concerns in patients with advanced cancer: an observational study at Regional Cancer Centre, India. Am J Hosp Palliat Me. 2010;27(5):316-9.

https://doi.org/10.1177/1049909109358309

40. Simha S, Noble S, Chaturvedi SK. Spiritual concerns in Hindu cancer patients undergoing palliative care: A qualitative study. Ind J

Palliative Care. 2013;19(2):99. https://doi.org/10.4103/0973-1075.116716

41. Dam A. Wading through quicksand: Palliative Care, Spirituality and Sanatan Dharma. Chennai: Notion Press; 2015.

42. Chaturvedi SK. Spiritual issues at end of life. Indian J Palliative Care. 2007;13(2):48. https://doi.org/10.4103/0973-1075.38899

43. Munday D, Haraldsdottir E, Manak M, Thyle A, Ratcliff C. Rural palliative care in North India: rapid evaluation of a programme using a realist mixed method approach. Ind J Pall Care (In press).

\section{Peer Reviewed}

Competing Interests: None declared.

Correspondence: Daniel Munday, International Nepal Fellowship, Nepal. daniel.munday@inf.org

Cite this article as: Munday D, Powys R. Reflections on the challenges and opportunities for palliative care in Nepal. Christian Journal for Global Health. Nov 2017; 4(3):12-20. https://doi.org/10.15566/cigh.v4i3.194

(C) Munday D, Powys R. This is an open-access article distributed under the terms of the Creative Commons Attribution License, which permits unrestricted use, distribution, and reproduction in any medium, provided the original author and source are properly cited. To view a copy of the license, visit http://creativecommons.org/licenses/by/4.0/

$$
\text { www.cjgh.org }
$$

Nov 2017. Christian Journal for Global Health 4(3):12-20 